\title{
A pós-graduação stricto sensu, a avaliação e suas controvérsias
}

\section{The postgraduate stricto sensu studies, its evaluation, and controversies}

\author{
Maria Cristina de Oliveira Cardoso \\ Programa de Pós-Graduação em História das Ciências e das Técnicas e Epistemologia \\ (HCTE), Universidade Federal do Rio de Janeiro (UFRJ). \\ mcristinaocardoso@gmail.com \\ orcid.org/0000-0001-8897-4974
}

\section{Regina Maria Macedo Costa Dantas}

Programa de Pós-Graduação em História das Ciências e das Técnicas e Epistemologia (HCTE), Universidade Federal do Rio de Janeiro (UFRJ).

regina@hcte.ufrj.br

orcid.org/0000-0001-9782-2008

\begin{abstract}
Resumo. Plano Nacional de Pós-graduação objetivando qualidade. Uma colcha de retalhos que nos leva aos critérios de avaliação. Um modelo de avaliação que fomenta controvérsias há mais de 40 anos. Neste trabalho traremos duas pequenas historiografias: a primeira sobre a avaliação dos cursos de pós-graduação stricto sensu no Brasil realizada pela CAPES/Coordenação de Aperfeiçoamento do Ensino Superior e a segunda sobre as reflexões de estudiosos brasileiros elaboradas ao longo dos anos sobre o modelo e os critérios de avaliação. Essas duas histórias traduzem os acertos e fracassos do modelo de avaliação contados por quem viveu e participou da história e demonstram o premente desejo de pesquisadores e entidades acadêmicas de adoção de novos critérios que reflitam a realidade de cada curso, de cada região do Brasil.
\end{abstract}

Palavras-chave: Avaliação. Pós-graduação. Produção científica.

Abstract. National Postgraduate Plan aiming at quality. A patchwork that takes us to the evaluation criteria. An evaluation that has been controversial for more than 40 years. This article brings two short historiographies: the first on the evaluation of stricto sensu graduate courses in Brazil carried out by CAPES / Coordination for the Improvement of Higher Education and the second on the thought of Brazilian scholars elaborated over the years on the evaluation criteria of 
postgraduate studies. These two stories reflect the successes and failures of the evaluation criteria demonstrate the urgent desire of researchers and academic entities to adopt new criteria that reflect the reality of each course, in each region of Brazil.

Keywords: Evaluation. Postgraduate. Scientific literature.

Recebido: 01/10/2018 Aceito: 27/10/2018 Publicado: 05/11/2018

\section{Introdução}

Garantir a performance de um programa de pós-graduação stricto sensu no Brasil é uma tarefa árdua. Além da necessidade de interagir e, por que não dizer, controlar a atuação acadêmica dos diversos atores que compõem os elementos de avaliação, existe a necessidade de compreender, articular e relacionar as informações escritas em diferentes documentos, elaboradas em diferentes datas. Todo este movimento, que muitas vezes pode passar desapercebido ao longo do ano, se evidencia nas atividades acadêmicas quando se aproxima a data de avaliação dos cursos.

Recentemente o debate sobre os critérios de avaliação ganhou novamente visibilidade após a divulgação pela CAPES do resultado da última avaliação relativa ao quadriênio 2013-2016. O desconforto com esse resultado levou Instituições como a Sociedade Brasileira para o Progresso da Ciência/SBPC e a Academia Brasileira de Ciências/ABC, entre outras, a participarem de discussões e elaborarem suas contribuições visando promover mudanças nos critérios de avaliação.

Para este trabalho traremos algumas reflexões e controvérsias de estudiosos brasileiros, reflexões de quem viveu e participou da história da avaliação da pós-graduação stricto sensu no Brasil. Trazemos duas pequenas historiografias: a primeira sobre a avaliação dos cursos de pós-graduação stricto sensu no Brasil realizada pela CAPES/Coordenação de Aperfeiçoamento do Ensino Superior e a segunda sobre as reflexões de estudiosos brasileiros elaboradas ao longo dos anos sobre o modelo e os critérios de avaliação. Este estudo é parte integrante de uma pesquisa de mestrado em andamento do programa de pós-graduação em História das Ciências, das Técnicas e Epistemologia/HCTE da Universidade Federal do Rio de Janeiro/UFRJ. Assim como a pesquisa de mestrado, este trabalho se propõe a utilizar dados abertos ou públicos. 


\section{CAPES e a Avaliação ${ }^{1}$}

O Sistema de Avaliação dos programas de pós-graduação no Brasil é composto por princípios e diretrizes. Hoje, esse processo de avaliação é sustentado por três pilares: a avaliação por pares, o foco na formação dos recursos humanos e a produção intelectual associada a esta formação.

A avaliação da pós-graduação no Brasil foi criada em 1976 e foi posteriormente escolhida como o instrumento para viabilizar o acesso ao auxílio financeiro disponibilizado pelas agências nacionais e internacionais. Mas foi em 1977 que o sistema de avaliação dos programas de pós-graduação no Brasil foi instituído. O primeiro sistema de avaliação estava baseado no I Plano Nacional de Pós-graduação/PNPG que tinha como objetivo a manutenção de um padrão de qualidade e a qualificação de docentes, entre outros. Em 1981, com a extinção do Conselho Nacional de Pós-graduação, a CAPES/ Coordenação de Aperfeiçoamento do Ensino Superior se torna responsável pela elaboração do II Plano Nacional de Pós-graduação. Foi a partir de 1981 que o Conselho Federal de Educação passou a utilizar as avaliações da CAPES como referência.

Novas mudanças ocorreram a partir de 1982. Neste ano a CAPES tomou a decisão de enviar para os programas de pós-graduação e instituições participantes, relatórios com os seus respectivos resultados da avaliação. Seria a primeira tentativa de dar transparência ao processo de avaliação. Outras mudanças ocorreram no ano seguinte, como por exemplo, a implantação de Coordenações do Processo de Avaliação constituídas por membros da comunidade acadêmica indicados pelas instituições participantes.

Em 1997, através da Portaria de $n^{\circ} 2264$, definiu-se o critério para validação nacional dos títulos de mestres e doutores da pós-graduação stricto sensu. A validade dos títulos passaria a estar vinculada ao resultado obtido pelos respectivos cursos de pós-graduação na avaliação da CAPES. Este fato foi um marco no modelo de avaliação. Ainda em 1997, após vários ${ }^{2}$ questionamentos sobre o modelo de avaliação aplicado, a CAPES convidou consultores internacionais para emitirem um parecer sobre os critérios de avaliação dos programas de pós-graduação. Essa comissão de consultores apresentou diversas recomendações que culminaram na Portaria de $\mathrm{n}^{\mathrm{o}} 1418$ de 1998. Esta Portaria estabeleceria um padrão de excelência baseado nos conceitos recebidos pelos programas de pós-graduação stricto sensu na avaliação da Capes. A partir desta Portaria, passaram a ser válidos os títulos dos mestres e doutores cujos cursos tivessem sido avaliados com conceito igual ou maior que 3 (em uma escala crescente de números inteiros de "1" a “7”). Também nesta época ocorreu a Implantação do Sistema Nacional de Pósgraduação/SNPG que trouxe a padronização da Ficha de Avaliação dos programas de pós-graduação. Em 2018, o critério de reconhecimento dos cursos mudou. A Portaria 182

\footnotetext{
${ }^{1}$ Todas as informações deste tópico foram extraídas do sítio da CAPES. Devido ao grande de número de páginas visitadas, relacionar todas nas referências faria a lista se torna extensa. Assim, nas referências será referenciada apenas a página principal do sítio da CAPES.

${ }^{2}$ As controvérsias serão apresentadas a seguir.
} 
de 14 de agosto de 2018 estabeleceu que seriam também desativados os programas compostos por mestrado e doutorado que recebessem conceito 3 ou os cursos apenas no nível de mestrado que forem avaliados com conceito 3 .

O Qualis-Periódicos, sistema de qualificação de veículos de publicação de produção científica, data de 1998. A padronização da Ficha de Avaliação, ocorrida nesse ano, fez com que todos os cursos fossem avaliados com os mesmos critérios. Este fato, associado ao aumento da produção científica, levou a CAPES a constatar a inviabilidade de continuar qualificando cada artigo/produção científica em cada avaliação. Até esta data a CAPES qualificava cada artigo publicado pelo corpo social dos programas de pósgraduação, individualmente, no momento da avaliação. Diante da quantidade de artigos a serem lidos e qualificados a decisão foi classificar os periódicos, veículos onde os programas de pós-graduação publicam sua produção científica. $\mathrm{O}$ fomento à pesquisa sempre esteve articulado com a avaliação dos programas de pós-graduação, o que poderia, segundo a CAPES, explicar o sucesso da pós-graduação no Brasil. Em 2000, o sistema Qualis sofreu algumas alterações, entre elas a inserção de uma limitação do número de periódicos que poderiam ser classificados no mais alto nível da classificação. A limitação foi de $25 \%$ do número total de periódicos de cada Área de Avaliação. Em 2010, a produção intelectual na categoria livros e a produção artística passaram a ser avaliadas sistematicamente - até então não existia um padrão de avaliação desses quesitos.

Outras mudanças ocorreram ao longo dos anos no SNPG, mudanças essas que alteraram indicadores e a forma de coleta de dados. A periodicidade da avaliação também mudou passando a ser quadrienal em 2014 - Resolução n5, de 11 de dezembro de 2014. Hoje, o SNPG tem como objetivo a formação pós-graduada de docentes para todos os níveis de ensino, formação de recursos humanos qualificados para o mercado não-acadêmico e o fortalecimento das bases científicas, tecnológicas e de inovação. O VI Plano Nacional de Pós-graduação/PNPG 2011-2020 traz novas diretrizes e estratégias para a política de pósgraduação e pesquisa do país. Um dos pontos relevantes apontados é o estímulo às experiências interdisciplinares com a criação de programas e áreas de concentração. Para termos uma ordem de grandeza a quantidade de cursos de pós-graduação no Brasil na década de 1960 era de 38 cursos, sendo 11 de doutorado e 27 de mestrado (VELLOSO, 2002). No ano de 2016, identificou-se no sítio da CAPES a existência de $4.177^{3}$ cursos de pós-graduação divididos em 49 áreas de avaliação que seguem uma mesma sistemática e conjunto de quesitos básicos estabelecidos pelo Conselho Técnico Científico da Educação Superior/CTC-ES.

\section{Controvérsias e Reflexões}

Nesse trabalho vamos relatar algumas controvérsias a partir de 1982, quando a CAPES decide enviar o relatório final de avaliação aos cursos de pós-graduação e às instituições

\footnotetext{
${ }^{3}$ Informação obtida em : <https://geocapes.capes.gov.br/geocapes/> último acesso 18/02/2018
} 
participantes. O jornal "O Estado de São Paulo", após ter acesso à algumas informações, publicou uma lista dos cursos que obtiveram os piores conceitos na avaliação da CAPES. Esta publicação fomentou uma ampla discussão sobre qualidade do ensino brasileiro, não só no meio acadêmico, mas também na população em geral. Segundo Castro e Soares (1983,p.63) a divulgação dos piores cursos no jornal teria ajudado a legitimar o sistema de avaliação, dando-lhe estabilidade. Para os autores estava claro a finalidade do resultado da avaliação: os cursos que obtivessem o conceito A ou B receberiam o apoio financeiro das agências governamentais. Ainda segundo os autores, o fato de existirem cursos em regiões pouco favorecidas, como por exemplo o norte e nordeste, não poderia influenciar na avaliação, nem tampouco eles poderiam receber tratamento diferenciado.

Fica assim entendido que os critérios de avaliação nada têm a ver com a história do curso, seus esforços ou as dificuldades que encontram. O tratamento diferenciado que se pode justificar em muitos casos não deve contaminar a atribuição do conceito. O extraordinário esforço de um grupo do Nordeste pode e deve ser apoiado, mas, no julgamento do resultado, será comparado com todos os demais, recebendo um conceito que meramente reflete suas realizações. (CASTRO, SOARES, 1983, p. 65-66)

Passados 10 anos, esta controvérsia ainda persistia. Mauricio Lima Barreto, membro do CTC e representante da Área de Saúde Coletiva da CAPES, levantou questões sobre comparabilidade entre diferentes áreas de conhecimento e a valoração das contribuições dos programas para o desenvolvimento social, econômico e cultural do país. No entendimento do autor, não deveria haver uma padronização da avaliação para áreas de conhecimento. Dever-se-ia buscar padrões de qualidade para cada área (BARRETO, 1998, p.73). É bom lembrar que este foi o ano da consolidação do modelo de Avaliação da CAPES que trouxe mudanças tais como o papel do Conselho Técnico Científico/CTC. Neste ano de 1998, o CTC passou a ter o direito de questionar as análises das Comissões de Área, podendo, inclusive, modificar os conceitos dados. Em 2005 este tema ainda era discutido. Segundo Horta e Moraes ${ }^{4}$, aquele foi um momento de luta por hegemonia dentro dos CTCs. Os autores afirmavam que o enquadramento resultante dos novos critérios de avaliação deixava de fora a Área de Humanidades:

[...] o quesito que realmente discrimina, no atual processo de avaliação da pósgraduação, é a produção bibliográfica, e nessa a qualidade dos veículos de divulgação. [...] Ao contrário do senso comum, um elevado tempo médio de titulação e um baixo número de titulados por docente, bem como um alto índice de evasão, pouco repercutem na avaliação do programa, embora sejam fatais na hora da distribuição de bolsas da CAPES, [...] Em outras palavras, esse parece o perverso círculo vicioso em que está entrando a pós-graduação brasileira: docentes de programas com alto conceito dedicam mais tempo à produção científica, garantindo a manutenção desses conceitos e o financiamento por parte dos órgãos que consideram fundamental o conceito no momento da distribuição de verbas (HORTA, MORAES, 2005.p.101)

\footnotetext{
${ }^{4}$ Maria Célia Marcondes de Moraes: Representante da área de Educação junto à CAPES (2001-2003) e membro da Comissão de Acompanhamento dos Programas de Pós-graduação em Educação da CAPES (2005, 2006). É membro do Comitê Assessor da Área de Educação do CNPq (2005-2008).
} 
O presidente da CAPES Abilio Afonso Baeta Neves em 2002, em uma entrevista, demonstrava conhecer o desconforto dos estudiosos com a avaliação, principalmente com a demanda de produção científica. Neves afirmava que os indicadores propostos seriam indicadores de excelência e que a internacionalização era a condição para se atingir uma formação altamente qualificada.

\begin{abstract}
Porque essa discussão que se reabriu sobre indicadores, padrões e parâmetros de excelência provocou inevitavelmente uma turbulência no interior de cada área e na relação entre as áreas. Essa turbulência tem tudo a ver com o fato de que nós mantivemos a avaliação da CAPES como um sistema único, ou seja, não tivemos na CAPES avaliações distintas por áreas de conhecimento. Queremos que os resultados da avaliação tenham alguma equivalência. (NEVES, 2002, p.7).
\end{abstract}

Ao longo dos anos, novos questionamentos foram surgindo e alguns colocavam em dúvida os critérios de classificação do Qualis. No ano de 2009, por exemplo, Rocha-eSilva, editor da Clinics da Faculdade de Medicina da USP, fez duras críticas às mudanças implantadas no Qualis questionando a limitação de $25 \%$ na quantidade de periódicos que poderia ser qualificada como $\mathrm{A}^{5}$. Segundo o autor, o "limite para cada área foi fixado por numerologia, sem nenhuma relação com a realidade da respectiva produção científica" $(2009$, p.1)

Mais de 40 anos depois da implantação da avaliação ainda existem questionamentos sobre os indicadores. Em 2014, Tourinho e Palha (2014, p.1) traziam em seu trabalho reflexões sobre os indicadores e sobre um possível processo de alienação produzido pela CAPES com anuência das universidades brasileiras. Os autores sugeriam que o critério de produção de conhecimento poderia afetar diretamente o objeto de trabalho dos professores e alunos na busca de se adequarem às regras. Segundo Tourinho e Palha (2014,p.7), impor uma produção científica, desconsiderando o perfil socioeconômico dos discentes e docentes e desconsiderando características e recursos locais, seria um reflexo da falta de representatividade de grupos fora do eixo sul e sudeste no Conselho Superior, principalmente grupos do norte do país.

\begin{abstract}
Aos que trabalham, nega-se o estabelecimento da sua relação com os produtos do seu trabalho e os parâmetros da sua própria história acadêmica. Não há independência. Essa alienação das concepções doutrinárias, filosóficas e materiais do trabalho produz um homem alienado, pois traz o desapossamento do trabalho. Não é, portanto, a satisfação de uma necessidade (nossa), mas apenas um meio para satisfazer necessidades exteriores a nós e, por isso, virase contra nós, porque, independente de nós, não nos pertence, pertence à Capes. (TOURINHO, PALHA, 2014, p.7).
\end{abstract}

As controvérsias sobre a avaliação não terminam e se renovam a cada divulgação de resultado. Em 2017 a avaliação foi tema central do Fórum Nacional de Pró-reitores de Pesquisa e Pós-graduação do Brasil/FOPROP. No documento elaborado no Fórum destacam-se críticas aos critérios de avaliação, entre elas às métricas iguais para todos os

\footnotetext{
${ }^{5}$ A classificação Qualis segue uma ordem alfabética e numérica conforme a seguir: A1, A2, B1, B2, B3, B4, B5, C, onde A1 tem a maior pontuação e B5 a menor pontuação. C não pontua
} 
programas. O documento também critica o excessivo peso numérico dado a produção científica. A FOPROP sugeriu a adoção de pesos diferentes atribuídos aos quesitos por área de avaliação, entre outros pontos (FOTROP, 2017). Neste mesmo ano, a ANINTERSH/Associação Nacional de Pesquisa e Pós-Graduação Interdisciplinar em Sociais e Humanidade, em um encontro promovido com os coordenadores dos cursos interdisciplinares, também fez críticas ao caráter produtivista e hierárquico das avaliações. Além da ANINTER-SH e FOPROP, uma proposta de revisão do modelo foi elaborada pela SBPC e encaminhada à CAPES em 2018. Destaca-se nesta proposta o entendimento de que o modelo atual estaria esgotado. $\mathrm{O}$ documento traz ainda sugestão de um processo de avaliação não produtivista e com perfis de indicadores diferenciados (RODRIGUES, 2018).

Um fato relevante levantado neste trabalho foi a necessidade de compilar informações de diferentes documentos que suportam a avaliação, para ter uma leitura completa dos critérios de avaliação - quase como a elaboração de uma colcha de retalhos Para se alinhavar esta colcha de retalhos os documentos de consulta da Área Interdisciplinar consultados foram: Relatório de Avaliação, Ficha de Avaliação, Documento de Área e o Regimento. Todos esses documentos datam de diferentes épocas ou ano. Quando lidos isoladamente, não trazem uma compreensão plena dos critérios de avaliação.

\section{Considerações Parciais}

Muitas outras reflexões ficaram fora deste trabalho. Apesar da longevidade da discussão, percebe-se que os pontos mais questionados se repetem ciclicamente. Questões como possibilidade de conceitos regionalizados, conceito por áreas, representatividade regional no Conselho se repetem e devem ser discutidas. Temos um país continental, com suas particularidades e regionalidades. Reproduzir ou tentar reproduzir um formato de avaliação de outros países, sem uma pequena antropofagia, talvez continue suscitando discussões, insatisfação e desigualdades nas universidades brasileiras. Entendemos que é necessário que estudiosos, entidades e instituições públicas se unam para buscar soluções que reflitam as necessidades de todos.

\section{Referências}

ANINTER, Associação Nacional de Pesquisa e Pós-graduação Interdisciplinar em Sociais e Humanidades. Carta de João Pessoa, 01/112017. Disponível em: $<$ http://www.aninter.com.br/CartasDocumentos/CartaJP2017.pdf >. Último acesso em $17 / 09 / 18$

BARRETO, Maurício Lima. O após da Avaliação da Pós-Graduação em 1998: para onde devemos seguir. INFOCAPES, Boletim Informativo da CAPES. Brasília v.6, n4, p.7173. Editora UnB, out/dez 1998. Disponível em: <https://www.capes.gov.br/images/stories/download/bolsas/Info4_98.pdf> 
CAPES, Coordenação de Aperfeiçoamento de Pessoal de Nível Superior. Disponível em: http://www.capes.gov.br/

CASTRO, Cláudio de Moura; SOARES, Gláucio Ary Dillon. Avaliando as avaliações da Capes. Revista Administração empresas, São Paulo, v. 23,n. 3, p. 63-73, Setembro1983

Disponível em: $<$ http://www.scielo.br/scielo.phpscript=sci_arttext\&pid=S003475901983000300007\&ln $\mathrm{g}=$ en\&nrm=iso $>$. Último acesso 14/08/2018.

FOPROP, Fórum de Pró-Reitores de Pesquisa e Pós-Graduação. Avaliação da Avaliação da Pós-graduação Brasileira: FOPROP , Brasília, nov/2017

HORTA,José Silvério Baía; MORAES, Maria Célia Marcondes de. O sistema CAPES de avaliação da pós-graduação: área de educação à grande área de ciências humanas. Revista Brasileira de Educação, n.30. p.95-116, dez.2005. Disponível em: <http://www.scielo.br/pdf/rbedu/n30/a08n30.pdf> Último acesso em 25/07/2018

NEVES, Abilio Afonso Baeta. Depoimento. INFOCAPES, Boletim Informativo Vol. 10, $\mathrm{N}^{\mathrm{o}} 4$ out/dez 2002. Disponível em: < $\mathrm{http}$ : //www.capes.gov.br/images/stories/download/bolsas/Infocapes10_4_2002.pdf > . Último acesso em 1/10/2018

ROCHA-E-SILVA, Mauricio. Carta Aberta ao Presidente da Capes: o novo Qualis, que não tem nada a ver com ciência do Brasil. Pró-Fono R. Atual.Cient.,Barueri, v.21,n.4,p.275-278,Dec.2009. Disponível em: <http://www.scielo.br/scielo.php?script=sci_arttext\&pid=S010456872009000400002\&1 ng=en\&nrm=iso. Último acesso em 1/10/2018

RODRIGUES, Marcelo. SBPC envia sugestões para um novo modelo de avaliação da Pós-Graduação no País. Soc.Bras.Prog da Ciência. Publicado em 11/04/2018. Disponível em:< http://portal.sbpcnet.org.br/noticias/sbpc-envia-sugestoes-novomodelo-de-avaliacao-da-pos-graduacao-no-pais/>. Último acesso: 15/07/2018

TOURINHO, Manoel Malheiros e PALHA, Maria das Dores Correia. A Capes, a universidade e a alienação gestada na pós-graduação. Cad. EBAPE.BR [online]. 2014, vol.12, n.2, pp.270-283 Disponível em: $<$ http://www.scielo.br/scielo.php?script=sci_arttext\&pid=S167939512014000200007\&1 ng=pt\&tlng=pt $>$. Último acesso em 10/08/2018.

VELLOSO, Jacques. Introdução. In: VELLOSO, Jacques (Org.). A pós-graduação no Brasil: formação e trabalho de mestres e doutores no país. Brasília: CAPES/UNESCO, 2002 